\title{
SYNTHESIS, CHARACTERISATION AND FLUORESCENCE SENSING PROPERTIES OF TETRADENTATE $N, N$ '-BIS(SALICYLIDENE)-1,3- PROPANEDIAMINE FOR METAL IONS DETECTION: PRELIMINARY STUDY
}

\author{
SITI KAUTSAR ANUAR, SITI KAMILAH CHE SOH* AND HAFIZA MOHAMED ZUKI
}

Faculty of Science and Marine Environment, Universiti Malaysia Terengganu, 21030 Kuala Nerus, Terengganu, Malaysia

*Corresponding author: sitikamilah@umt.edu.my

http://doi.org/10.46754/umtjur.2021.07.018

\begin{abstract}
Tetradentate Schiff base ligand namely $N, N^{\prime}$-bis(salicylidene)-1,3-propanediamine, containing -ONNO- donor set was successfully synthesised between salicylaldehyde and 1,3-diaminopropane using condensation reaction. The structure of the synthesised ligand was unambiguously determined by Fourier Transform Infrared (FTIR) spectroscopy, Nuclear Magnetic Resonance (NMR) spectroscopy and Thermogravimetric Analysis (TGA). The spectroscopic studies suggest that the central azomethine $(\mathrm{C}=\mathrm{N})$ group of tetradentate ligand can be assigned at vibration peak $1632 \mathrm{~cm}^{-1}$ and the chemical shift observed for $\mathrm{OH}$ proton appeared at very downfield. TGA curve shows around $80 \%$ weight loss occurred when the sample was heated at room-temperature up to $850^{\circ} \mathrm{C}$. Initial data show the ligand enhanced fluorescence spot upon increasing the concentration of $\mathrm{Zn}^{2+}$ and $\mathrm{Pb}^{2+}$. The response of ligand with $\mathrm{Zn}^{2+}$ and $\mathrm{Pb}^{2+}$ also inhibits the $\mathrm{C}=\mathrm{N}$ bond isomerisation and subsequently increased the intensity of fluorescence efficiency. Thus, the proposed tetradentate Schiff base ligand used as reagent sensing potentially has good capability in sensing application for metal ions detection.
\end{abstract}

Keywords: Tetradentate Schiff base, metal complexes, fluorescence sensing

\section{Introduction}

Heavy metals such as mercury $(\mathrm{Hg})$, cadmium $(\mathrm{Cd})$ and lead $(\mathrm{Pb})$ can be described as those with definite density exceeding $5 \mathrm{~g} / \mathrm{cm}^{-3}$. These metals have been thoroughly studied and frequently evaluated by international organizations like WHO for their effects on human health. The toxicity of heavy metals has proven to be a major threat and the negative effects on health, environment as well as living organisms have long been recognized (Jarup, 2003). According to Kang et al., (2014), in industrial and agriculture pollutants, heavy metal ions are pervasive, thus causing a major environmental issue in many places. Unlike many other pollutants, heavy metal ions are hard to degrade, yet they are easy to enrich human body through the food chain.

Zinc is the second most abundant metal ion among the varied major heavy metal ions in the human body and thus the detection of $\mathrm{Zn}^{2+}$ shows considerable interest in chemistry (Hens et al., 2014). The disorder of zinc ion metabolism can cause anaemia, growth retardation, skin abnormalities, and mental lethargy. In addition, deficiency of zinc can cause delayed growth, immunodeficiency, and also degeneration of the neurons. So, there is significant interest and importance for the detection of $\mathrm{Zn}^{2+}$ in the samples (Ackland \& Michalzyk, 2006).

Lead is classified among the most harmful and cumulative pollutants of the environment that threatens all biological systems by exposure to air, water and food sources. Lead is among the most frequently found as global environmental pollutants in manufacturing areas, and animals could be exposed to lead easily. In addition, excessive consumption of lead may cause bad animal performance, poisoning and death (Assi et al., 2016). 
Schiff base ligand is versatile $\mathrm{C}=\mathrm{N}$ (imine) compound with a wide spectrum of biological activity and complex incorporation of metals that have shown some degree of antibacterial, antifungal, antitumor and anti-inflammatory interaction. They are ketone or aldehyde condensation products with primary amines and were first reported in 1864 by Hugo Schiff (Xavier \& Srividhiya, 2014). Schiff base ligands involving different donor atoms (such as $\mathrm{N}, \mathrm{O}$, $\mathrm{S}$, etc.) exhibit wide biological activity and are of particular concern due to the wide variety of ways in which they have been linked to transition metal ions. Because of their coordination chemistry, Schiff bases have been considered as important ligands for decades and can be easily prepared and connected to a different type of metal ions (Joshi et al., 2014). Therefore, fluorescence techniques have been commonly used in the identification of metal ions, with the benefits of sensitivity, simple operation, and real-time tracking with quick response time (Guo et al., 2019). In this study, synthesis, characterisation and fluorescence sensing properties of tetradentate Schiff base ligand, $N, N$ '-bis(salicylidene)-1,3-propanediamine for metal ion detection have been focused on and the preliminary studies have been carried out.

\section{Materials and Methods}

\section{Chemicals}

Pure chemicals of 1,3-diaminopropane and salicylaldehyde were purchased from Merck and Aldrich, respectively. Absolute ethanol (95\%) ethanol $(70 \%)$, zinc sulphate $\left(\mathrm{ZnSO}_{4}\right)$ and lead chloride $\left(\mathrm{PbCl}_{2}\right)$ were used to prepare metal ion stock solutions. The chloroform- $d\left(\mathrm{CDCl}_{3}\right)$ was available as a solvent to record ${ }^{1} \mathrm{H}$ NMR and ${ }^{13} \mathrm{C}$ NMR spectra. All of the chemicals were used as received without further purification.

\section{Instrumentation}

Fourier-transform infrared spectroscopy (FTIR) was performed using Perkin-Elmer Spectrum 100 Spectrometer. FTIR spectrum was obtained using $\mathrm{KBr}$ pellet method. The absorption was recorded in the range of 4000-400 $\mathrm{cm}^{-1}$. Nuclear Magnetic Resonance (NMR) spectra of ${ }^{1} \mathrm{H}$
NMR and ${ }^{13} \mathrm{C}$ NMR were obtained using Bruker Avance III $400 \mathrm{MHz}$ spectrometer, using $\mathrm{CDCl}_{3}$ as the solvent. Thermogravimetric Analyzer (TGA) was performed using Mettler Toledo TGA/SDTA $851^{\circ}$ with a heating rate of $15^{\circ} \mathrm{C} /$ min over the temperature range between $30-850$ ${ }^{\circ} \mathrm{C}$. Ultraviolet-Visible (UV-Vis) spectra were recorded on a Shimadzu SPD-10A. The stock solution of ligand with the concentration of 0.01 $\mathrm{M}$ was diluted for several series with the new concentration of $1 \times 10^{-3} \mathrm{M}, 1 \times 10^{-4} \mathrm{M}, 1 \times 10^{-5}$ $\mathrm{M}$ and $1 \times 10^{-6} \mathrm{M}$ using ethanol as solvent. The emission of data was collected using Cary Eclipse Fluorescence Spectrophotometer.

\section{Synthesis of Ligand}

Salicylaldehyde (0.4884 g, $4.00 \mathrm{mmol})$ was mixed with $10 \mathrm{~mL}$ of absolute ethanol in 3 neck round bottom flasks. Then, 1,3-diaminopropane $(0.1482 \mathrm{~g}, 2.00 \mathrm{mmol})$ was added into that flask and the mixture was refluxed for 6 hours. The yellow precipitate was formed. The precipitate was filtered and left until totally dry. Ethanol solution was used as solvent to recrystallize the yellow precipitate.

\section{Fluorescence Experiments}

A stock solution of zinc and lead with the concentration of $0.001 \mathrm{M}$ was initially prepared by dissolving metal ions in distilled water. The stock solutions were then diluted to appropriate concentrations for further experiment. All fluorescence emission spectra were recorded in the wavelength from $300 \mathrm{~nm}$ to $650 \mathrm{~nm}$. The slit widths for excitation and emission were both 10 $\mathrm{nm}$.

\section{Results and Discussion}

The ligand was successfully synthesized by condensation reaction between salicylaldehyde and 1,3-diaminopropane under mild conditions (Scheme 1). The reaction progress was monitored using TLC. The structure of the ligand was confirmed by FTIR and NMR spectroscopies as well as TGA. FTIR data (Table 1) show a vibration band at $1632 \mathrm{~cm}^{-1}$ which can be assigned to the stretch of imine $(-\mathrm{C}=\mathrm{N}-)$ group 
in the ligand molecule. The vibration band at $3457 \mathrm{~cm}^{-1}$ associated with alcohol stretching group while $1582 \mathrm{~cm}^{-1}$ was assigned as (-C-C aromatic) symmetrical group in this Schiff base ligand.

Scheme 1: Synthesis route of tetradentate Schiff<smiles>O=Cc1ccccc1O</smiles><smiles>NCCC[NH3+]</smiles><smiles>Oc1ccccc1/C=N/CCC/N=C/c1ccccc1O</smiles>

base ligand

Table 1: FTIR peak assignment of tetradentate ligand

\begin{tabular}{lccccr}
\hline \multirow{2}{*}{ Compound } & $\mathbf{5}(\mathbf{O}-\mathbf{H})$ & $\mathbf{n}(\mathbf{C}=\mathbf{N})$ & $\mathbf{n}(\mathbf{C}=\mathbf{C}$ aromatic $)$ & $\mathbf{n}(\mathbf{C}-\mathbf{N})$ & $\mathbf{n}(\mathbf{C}-\mathbf{O})$ \\
\cline { 2 - 6 } & 3457 & 1632 & 1582 & 1281 & 1011 \\
\hline $\begin{array}{l}N, N^{\prime} \text {-bis(salicylidene)-1,3- } \\
\text { propanediamine }\end{array}$ & & & & & \\
\hline
\end{tabular}

The ${ }^{1} \mathrm{H}$ NMR spectrum obtained for synthesised ligand in chloroform- $d\left(\mathrm{CDCl}_{3}\right)$ with their assignment is given in Figure 1. The proton of azomethine $\mathrm{HC}=\mathrm{N}$ was exhibited at the downfield $\mathrm{d}_{\mathrm{H}} 8.40 \mathrm{ppm}$. The multiplet dan triplet resonances were observed at shielded regions, at two different environments $\mathrm{d}_{\mathrm{H}} 2-13-2.16$ ppm and $\mathrm{d}_{\mathrm{H}} 3.73-3.76 \mathrm{ppm}$ accordingly which were allocated for $\mathrm{C}-\mathrm{CH}_{2}-\mathrm{C}$ and $\mathrm{N}-\mathrm{CH}_{2}$. The distinctive multiplet resonance appeared in the range of $d_{H} 6.89-7.36$ ppm was attributed to the presence of aromatic protons for synthesized ligand.
Meanwhile, thermal analysis provides significant information about the structural feature and preferential ligation of the different groups directly attached to and/or associated in the compound (Soliman et al., 2000). The ligand was thermally stable up to $230{ }^{\circ} \mathrm{C}$ and above this temperature it started to decompose. Figure 2 reveals a decrease in mass between the temperature regions which may be due to the dissociation of solvent and water molecules and the sample degradation (Popa et al., 2006). The thermogram of tetradentate ligand shows around $90 \%$ in weight loss occurred when the sample was heated up to $850{ }^{\circ} \mathrm{C}$

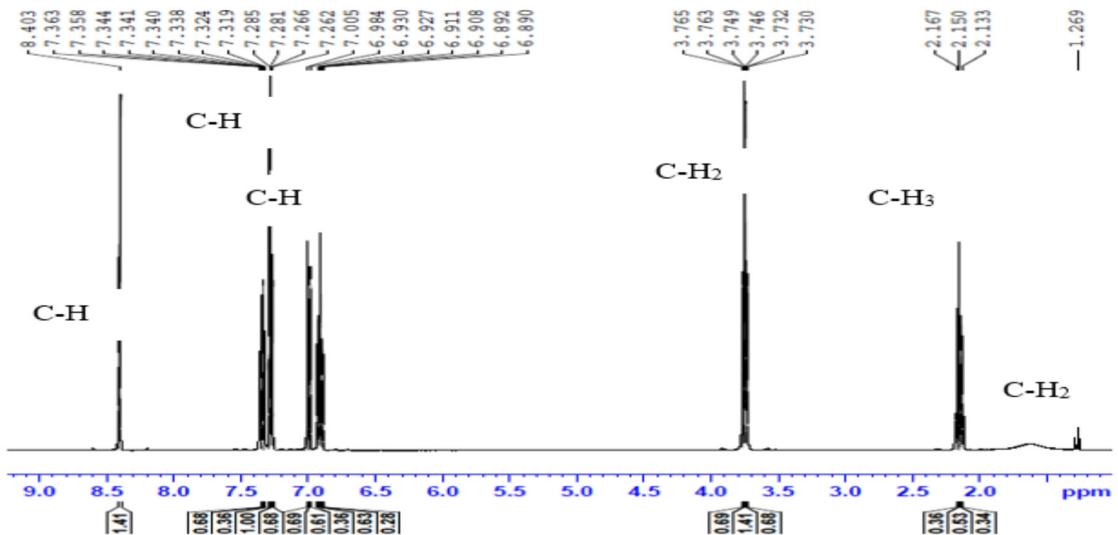

Figure 1: ${ }^{1} \mathrm{H}$ NMR spectrum of tetradentate Schiff base ligand 


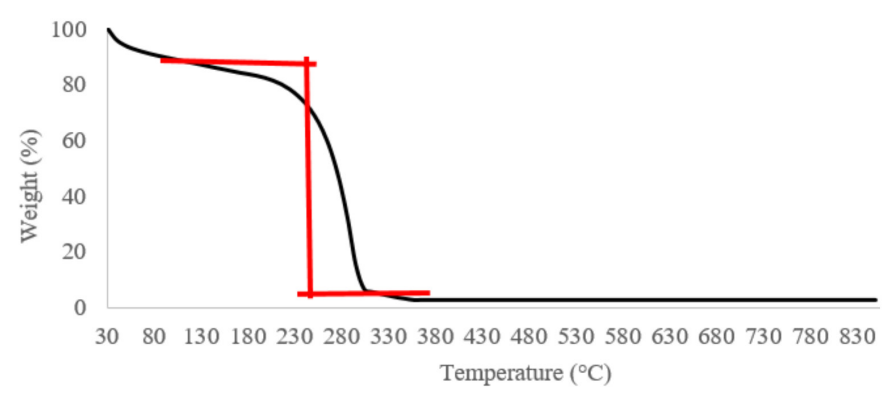

Figure 2: TGA thermogram of tetradentate Schiff base ligand

The UV-visible analysis of ligand was recorded in the $300-800 \mathrm{~nm}$ range in ethanol solution with the variety of concentrations between $1^{\prime} 10^{-2} \mathrm{M}$ until $1^{\prime} 10^{-6} \mathrm{M}$ (Figure 3). In the electronic spectra of ligand, the absorption band observed within the range of 350-450 nm was most probably due to the transition of $\mathrm{p} \AA \mathrm{p}^{*}$ in the benzene ring or $\mathrm{n}{ }^{\circledR} \mathrm{p}^{*}$ of $\mathrm{C}=\mathrm{N}$ chromophore, corresponding to the ligand (Fraser \& Bosnich, 1994). It can be found that the maximum absorption wavelength obtained at $395 \mathrm{~nm}$ with $1^{\prime} 10^{-5} \mathrm{M}$ which is the most suitable for sensing reagent due to high intensity of peak (Sun et al., 2014). As can be observed, the concentration of $1^{\prime} 10^{-5} \mathrm{M}$ provides optimum shoulder in the region which involves molecular essentially localized on the $\mathrm{C}=\mathrm{N}$ group and benzene ring (Asadi et al., 2011). The wavelength at 395 nm was also selected as ligand excitation for fluorescence study.

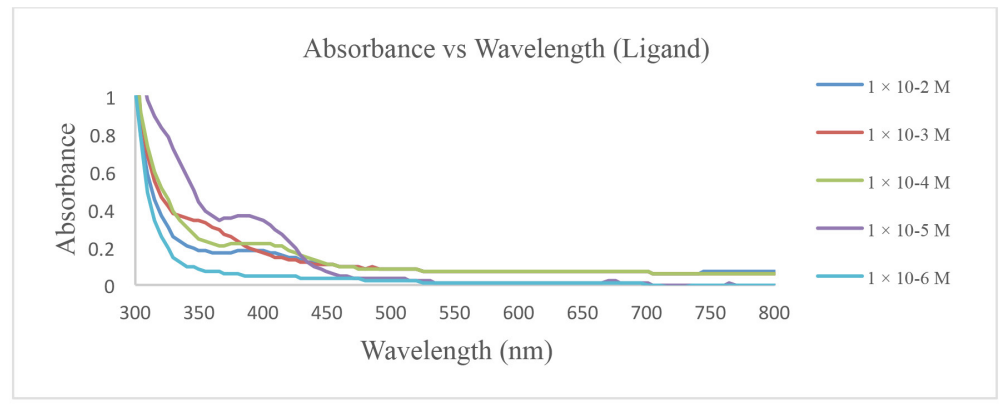

Figure 3: Progression of UV-vis spectra of ligand with different concentrations

Furthermore, the fluorescence study was investigated for 1 ' $10^{-5} \mathrm{M}$ solution using excitation wavelength at $395 \mathrm{~nm}$. Two types of metal ions have been tested which are $\mathrm{Zn}^{2+}$ and $\mathrm{Pb}^{2+}$. Excitation and emission-based response of ligand with metals ion are shown in Figure 4. The results show that the fluorescence enhancement on $\mathrm{Pb}^{2+}$ ion is higher compared to $\mathrm{Zn}^{2+}$ ion due to the excellent selectivity and sensitivity towards
$\mathrm{Pb}^{2+}$ with binding site of tetradentate ligand (Wan et al., 2015). The fluorescence intensities were increased according to the increased concentration ion of metals and saturates after one equivalent has been achieved. Hens et al., (2014) also reported that the changes of colour in solution may have occurred due to the decrease of absorption peak during the fluorescence studies. 

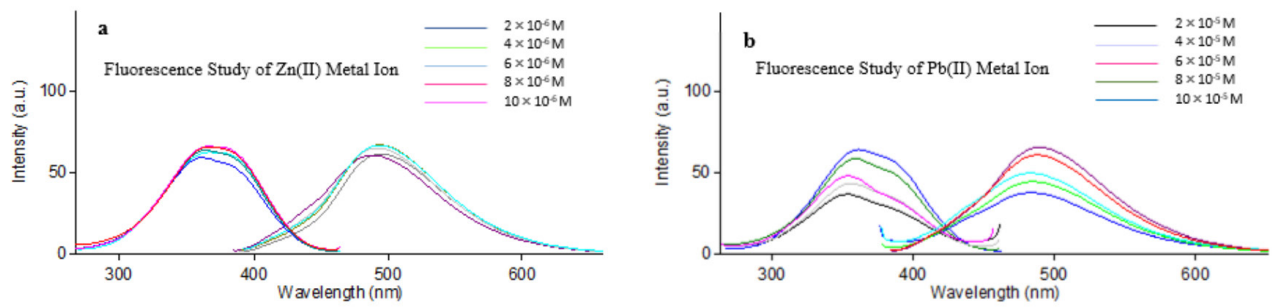

Figure 4: Fluorescence spectra of (a) $\mathrm{Zn}^{2+}$ and (b) $\mathrm{Pb}^{2+}$

Figure 5 exhibits calibration curves of metal ions for $\mathrm{Pb}^{2+}$ and $\mathrm{Zn}^{2+}$ with the ligand solution of $1^{\prime} 10^{-5} \mathrm{M}$. The $\mathrm{Zn}^{2+}$ ion that have low absorbance compared to other metal ion which leads to the formation of a stable complexes with the ligand as a sensing reagent (Andiappan et al., 2018). When a higher concentration of each metal was used, the fluorescence enhancement exhibited a linear response versus amount of the metal ion with the correlation coefficient for $\mathrm{Zn}^{2+}$ is 0.9895 and $\mathrm{Pb}^{2+}$ is 0.9876 , respectively. The results indicate that the ligand can be used for metals ion detection in a wide concentration range.
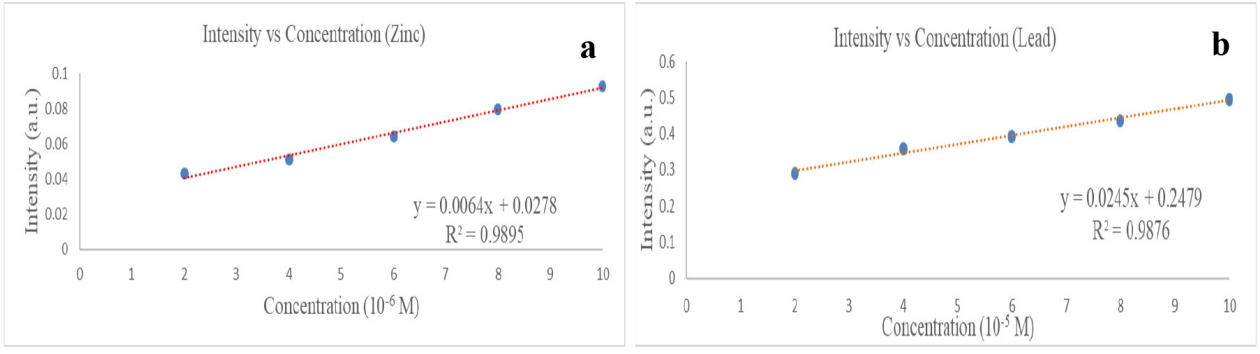

Figure 5: Fluorescence calibration curves of $\mathrm{Zn}^{2+}$ (a) and $\mathrm{Pb}^{2+}$ (b)

\section{Conclusion}

A turn-on fluorescence probe containing a Schiff base as metal binding site for zinc ion and lead ion has been synthesised through condensation reaction. The chemical structure and spectral properties were carefully characterized using FTIR spectroscopy, NMR spectroscopy and TG analysis. Selective binding with metal ions $\left(\mathrm{Zn}^{2+}\right.$ and $\mathrm{Pb}^{2+}$ ) greatly increased the fluorescence of the probe due to the formation of a rigid structure between the imine groups. The complexation between ligand and metal produced a large chelation-enhanced fluorescence effect, leading to the fluorescence enhancement. The method allows a simple and effective way for visual $\mathrm{Zn}$ (II) and $\mathrm{Pb}$ (II) detection.

\section{Acknowledgements}

The authors would like to thank the Faculty of Science and Marine Environment (FSSM), Centre of Research and Field Service (CRAFS) and the Institute of Marine and Biotechnology, Universiti Malaysia Terengganu for the research facilities.

\section{References}

Ackland, M. L., and Michalzyk, A. (2006). Zinc deficiency and its inherited disorders. Genes \& Nutrition, 1(1), 41-50. doi:10.1007/ BF02829935

Andiappan, K., Sanmugam, A., Deivanayagam, E., Karuppasamy, K., Kim, H-S. \& Vikraman, D. (2018) In vitro cytotoxicity 
activity of novel Schiff base ligandlanthanide complexes. Nature Research Journal. doi:10.1038/s41598-018-21366-1

Asadi, M., Sepehrpour, H. \& Mohammadi, K. (2011). Tetradentate Schiff base ligands of 3,4-diaminobenzophenone: Synthesis, characterization and thermodynamics of complex formation with $\mathrm{Ni}(\mathrm{II}), \mathrm{Cu}(\mathrm{II})$ and $\mathrm{Zn}(\mathrm{II})$ metal ions. Journal of the Serbian Chemical Society, 76(1), 63-74. doi: 10.2298/JSC100104004A

Assi, M. A., Hezmee, M. N. M., Haron, A. W., Sabri, M. Y. M. \& Rajion, M. A. (2016). The detrimental effects of lead on human and animal health. Veterinary World, 9(6): 660671. doi:10.14202/vetworld.2016.660-671

Fraser, C. \& Bosnich, B. (1994). Bimetallic reactivity. Investigation of metal-metal interaction in complexes of a chiral macrocyclic binucleating ligand bearing 6-and 4-coordinate sites. Inorganic Chemistry, 33, 338-346. doi:10.1021/ ic00080a024

Guo, Z., Wang, X., Wei, P. Gao, Y. \& Li, Q. (2019). Highly selective fluorescent probe for the detection of copper(II) and its application in live cell imaging. Journal of Analytical Methods in Chemistry. doi:10.1155/2019/8130767

Hens, A., Maity, A., \& Rajak, K. K. (2014). N,N coordinating Schiff base ligand acting as a fluorescence sensor for zinc(II) and colorimetric sensor for copper(II), and zinc(II) in mixed aqueous media. Inorganica Chimica, 423(2014): 408-420. doi:10.1016/j.ica.2014.08.024

Jarup, L. (2003). Hazards of heavy metal contamination. British Medical Bulletin, 68(1):167-182. doi:10.1093/bmb/ldg032 .
Joshi, K. R., Rojivadiya, A. J., \& Pandya, J. H. (2014). Synthesis and spectroscopic and antimicrobial studies of Schiff base metal complexes derived from 2-hydroxy3-methoxy-5-nitrobenzaldehyde. International Journal of Inorganic Chemistry. doi:10.1155/2014/817412

Kang, H., Lin, L., Rong, M., \& Chen, X. (2014). A cross-reactive sensor array for the fluorescence qualitative analysis of heavy metal ions. Talanta, 129(2014): 296-302. doi:10.1016/j.talanta.2014.05.054

Popa, A., Plesu, N., Sasca, V., Kis, E. E. and Neducin, R. M. (2006). Physicochemical Features of Polyaniline Supported Heteropolyacids. Journal of Optoelectronics and Advance Materials. 8, 1944-1950. doi:10.1.1.524.7616

Soliman, A. A., Ali, S. A., Khalil, M. M. H. \& Ramadan, R. M. (2000). Thermal studies of chromium, molybdenum and ruthenium complexes of chloranilic acid. Thermochimica Acta, 359(1): 37-42. doi. org/10.1016/S0040-6031(00)00486-X

Sun, J., Yu, T., Yu, H., Sun, M. Li, H., Zhang, Z., Jiang, H. \& Wang, S. (2014). Highly efficient turn-on fluorescence detection of zinc(II) based on multi-ligand metal chelation. Journal of Analytical Methods, 6(17): 67686773. doi.org/10.1039/C4AY00844H

Wan, Q., Zhuo, J., Lin, C. \& Yuan, Y. (2015). A simple and highly selective 2,2-diferrocenylpropane-based multichannel ion pair receptor for $\mathrm{Pb}^{2+}$ and $\mathbf{H S O}_{4}^{-}$. Dalton Transactions, 44, 57095796. doi:10.1039/C4DT03862B

Xavier, A., \& Srividhya, N. (2014). Synthesis and study of Schiff base ligands. Journal of Applied Chemistry, 7(11): 6-15. doi:10.9790/5736-071110615 